\title{
O ESCÂNDALO POLITICO DO "PETROLÃO" E A INTERSEÇÃO ENTRE CAMPOS SOCIAIS: análise discursivo-textual de cadeias de gênero em notícias
}

\author{
Maria Eduarda Gonçalves Peixoto \\ (Universidade Estadual do Ceará) \\ https://orcid.org/0000-0001-6613-8756
}

\section{RESUMO:}

Tendo como horizonte teórico-metodológico a Análise de Discurso Crítica, particularmente quanto à vertente dialéticorelacional, com base em Fairclough (1985, 1989, 2000, 2001a, 2001b, 2003) e Chouliaraki e Fairclough (1999), faz-se uma análise discursivo-textual de notícias online sobre o escândalo político do "Petrolão" publicadas pelas revistas semanais Veja e Carta Capital, entre 2014 e 2016, com foco sobre as cadeias de gênero (FAIRCLOUGH, 2001, 2003). O objetivo é descrever como as instâncias discursivas de mídia corporativa e alternativa encadeiam gêneros de distintas esferas sociais no processo de significação do evento. A investigação revela a relação sistemática entre gêneros e práticas de domínios institucionais e a configuração constituinte do escândalo na interseção constituinte entre os campos sociais da política, do judiciário e da mídia.

PALAVRAS-CHAVE: escândalo político; discurso; cadeia de gênero;

\section{THE "PETROLÃO" POLITICAL SCANDAL AND THE INTERSECTION BETWEEN SOCIAL FIELDS: \\ discursive-textual analysis of gender chains in news}

\section{ABSTRACT:}

Based on the theoretical-methodological framework of Critical

Discourse Analysis, particularly regarding the dialecticalrelational aspect, based on Fairclough (1985, 1989, 2000, 2001a, 
2001b, 2003) and Chouliaraki and Fairclough (1999), an analysis is made. textual discourse of online news about the "Petrolão" political scandal published by the weekly magazines Veja and Carta Capital, between 2014 and 2016, focusing on gender chains (FAIRCLOUGH, 2001, 2003). The objective is to describe how the discursive instances of corporate and alternative media chain genres from different social spheres in the event meaning process. The investigation reveals the systematic relationship between the genders and practices of institutional domains and the constituent configuration of the scandal at the constituent intersection between the social fields of politics, the judiciary and the media.

KEYWORDS: political scandal; discourse; gender chain;

\section{Notas introdutórias: contextualizando o "Petrolão"}

No Brasil, em março de 2014, a Polícia Federal (PF) deflagrou o que logo passou a ser considerada a maior investigação de corrupção e lavagem de dinheiro da história do país, a assim denominada Operação Lava Jato. Com um histórico de mais de cinquenta fases de desenvolvimento até o final do segundo semestre de 2019, a operação surgiu quando a Justiça Federal do Paraná, investigando desde 2009 as organizações criminosas Dolce Vita, Bidone, Casablanca e Lava Jato, unificou-as em 2013 sob a alcunha desta última. Tais organizações, lideradas por diferentes doleiros, realizavam crimes diversos, desde sonegação de impostos a contrabando de pedras valiosas, tendo destaque um esquema sofisticado de pagamento de propinas envolvendo grandes empreiteiras, parlamentares e diretores e gerentes de empresas públicas.

Entre agosto e setembro de 2014, à véspera da eleição presidencial protagonizada por Dilma Rousseff, do Partidos dos Trabalhadores (PT), então presidente e candidata à reeleição, e por Aécio Neves, do Partido da Social Democracia Brasileira (PSDB), senador e principal adversário, veio à tona o escândalo da Petrobrás, ou "Petrolão", tal como intitulado pela imprensa corporativa à época, 
empregando uma expressão que nos faz lembrar o escândalo do "Mensalão", de 2005. Apesar das proporções do escândalo e de seus prejuízos às imagens dos envolvidos, a chapa formada por Dilma Rousseff e pelo vice Michel Temer, do Movimento Democrático Brasileiro (MDB, antigo Partido do Movimento Democrático Brasileiro, PMDB) venceu as eleições. O escândalo, no entanto, não perdeu fôlego na mídia e começou a assombrar os primeiros meses do segundo mandato presidencial de Dilma Rousseff.

No início de 2015, em um contexto de alta dos juros e da inflação, crescente desemprego e contração econômica, a base do governo na Câmara dos Deputados enfraqueceu-se. As crises econômica e governamental foram somadas aos índices de insatisfação popular, alimentada pelos novos desdobramentos midiáticos do "Petrolão", que, a essa altura, atingia em cheio a Câmara dos Deputados e o Senado Federal. Em março do mesmo ano, milhares de brasileiros foram às ruas em protestos que, entre diversas reivindicações, como intervenção militar, pautavam-se majoritariamente na reprovação da presidente reeleita, promovendo panelaços ${ }^{1}$ e manifestações.

Nesse clima de forte tensão, em dezembro de 2015, o então presidente da Câmara dos Deputados, Eduardo Cunha (MDB) imediatamente após o partido PT ter anunciado apoio à cassação do seu mandato no julgamento pelo qual passava no Conselho de Ética da casa, em decorrência de seu envolvimento em casos investigados pela Operação Lava Jato - aceitou o pedido de impeachment de Dilma Rousseff._O pedido sustentou-se, mais particularmente, na denúncia de crime de responsabilidade fiscal, segundo a Lei $\mathrm{N}^{\circ}$ 13.255 do Código Civil, com base na qual argumentou-se que o Governo Dilma teria feito empréstimos de bancos federais ao Tesouro a fim de manter os programas sociais vigentes, o que ficou popularizado pela expressão "pedaladas fiscais".

Em maio de 2016, a imprensa circulou o áudio de uma

\footnotetext{
${ }^{1}$ O termo "panelaço", como explicam Colombo e Martelli (2015), faz referência a uma forma de protesto criada popularmente na América Latina nos anos 70, época em que, contra os regimes autoritários, pessoas insatisfeitas com determinado governo ou figura política manifestavam sua reprovação, especialmente mediante à queda de poder aquisitivo de suas classes, através de batidas de panelas ou outros utensílios metálicos de cozinha.
} 
conversa, ocorrida em março do mesmo ano, poucos dias antes da votação do impedimento pelos deputados, entre o Ministro do Planejamento e senador licenciado Romero Jucá (MDB-RR), alvo de inquéritos no Supremo Tribunal Federal (STF) decorrentes da Lava Jato, e o ex-presidente da Transpetro, subsidiária da Petrobrás, Sérgio Machado. Na gravação, o senador Romero Jucá, com receio de as investigações da Lava Jato chegarem a novos líderes da política e do setor empresarial, afirmou que seria urgente encontrar uma solução para "estancar a sangria" . Esta solução, segundo o áudio vazado, seria fazer um "grande acordo nacional" para levar o vice-presidente Michel Temer a ocupar a liderança do poder executivo. O então senador mencionou, ainda, que mantinha diálogo com "ministros do Supremo" e com "comandantes militares", os quais não nomeou, para garantir o tal acordo. Embora o conteúdo da conversa, trazido a público em um cenário marcado por contradições e contestações acerca da baliza jurídica do pedido de impeachment, em agosto de 2016 Dilma Rousseff foi destituída de seu cargo de Presidente da República do Brasil. O escândalo da Petrobrás, especialmente com o impeachment, promoveu uma ruptura irreconciliável do laço da soberania popular no país, com efeitos sobre a radicalização de tensionamentos e antagonismos sociais nas eleições presidenciais seguintes, em 2018.

O agravamento dos conflitos desdobrados com o "Petrolão", racionalizados por metanarrativas que definiram o momento histórico do país, de um lado, segundo a retórica do combate à corrupção, da defesa da pátria e do pleno funcionamento das instituições, e, de outro, como golpe de estado que pretendeu aniquilar a agenda política de centro-esquerda iniciada em 2003 com o Governo Lula, tem indicado que o uso tradicional que se tem feito da expressão "escândalo político" não parece mais inteiramente válido ou suficiente. A concepção de escândalo político amplamente compartilhada concebe o evento em termos da publicização de

\footnotetext{
${ }^{2}$ Neste parágrafo, as expressões entre as aspas foram retiradas do áudio original disponibilizado pela Folha de São Paulo em: $<$ http://www1.folha.uol.com.br/poder/2016/05/1774018-em-dialogos-gravados-jucafala-em-pacto-para-deter-avanco-da-lava-jato.shtml>. Acesso em: 24 abr. 2019.
} 
transgressões a leis, normas ou convenções de conduta praticadas por determinada figura política, que pode ter sua imagem prejudicada e sofrer condenações no âmbito da justiça (THOMPSON, 2002). No entanto, essa concepção não consegue dar conta de aspectos importantes em torno da constituição do evento e da cultura do escândalo político no Brasil. O caso "Petrolão", nesses termos, demonstra que o escândalo político diz muito mais sobre o funcionamento das estruturas de poder no país do que sobre a imagem de um político ou partido em particular.

Nessa perspectiva, venho argumentar que, surgindo o escândalo político numa situação de anomia, parecendo-nos confuso em virtude dos jogos ocultos de poder nele implicados, o aspecto do evento cuja análise abre caminho para leituras críticas mais avançadas é o da sua dimensão discursivo-textual. Não pretendo, com isso, indicar o esgotamento de categorias privilegiadas na análise de escândalos, como a corrupção, tampouco afirmar que tudo no evento se reduz à linguagem (stricto sensu). Minha argumentação, neste artigo, caminha na direção de evidenciar a razoabilidade de se considerar o texto e o discurso como conceitos e categorias operacionais relevantes para a análise socialmente orientada do escândalo político no escopo de uma ontologia crítica.

Para isso, apresento um recorte da minha pesquisa de doutoramento, que consiste em uma análise de discurso crítica textualmente orientada do "Petrolão". Mais especificamente, neste artigo, tendo como horizonte teórico-metodológico a Análise de Discurso Crítica, particularmente quanto à vertente dialéticorelacional, com base em Fairclough (1985, 1989, 2000, 2001a, 2001b, 2003) e Chouliaraki e Fairclough (1999), exibo uma análise discursivo-textual de notícias publicadas pelas revistas semanais Veja e Carta Capital, entre 2014 e 2016, com o objetivo de descrever como as instâncias discursivas de mídia corporativa e alternativa (re)contextualizam gêneros textuais de distintas esferas sociais no processo de significação do "Petrolão". A análise das cadeias de gêneros articuladas nas notícias revela, como veremos adiante, a configuração constituinte do escândalo, permitindo identificar os domínios da estrutura social que participam da constituição do evento. 


\section{Discurso, texto e cadeia de gênero}

Situada na ADC, que fornece aos estudos críticos da linguagem uma metodologia qualitativa interpretativa, esta pesquisa desenvolve uma análise de discurso textualmente orientada (ADTO) do "Petrolão". Conforme esclarece Magalhães (2004, p. 117), a especificidade da ADTO reside em sua aposta na "análise detalhada dos textos como janelas a iluminarem as práticas sociais". Chouliaraki e Fairclough (1999, p. 21) entendem práticas sociais como "modos habituais, situados em determinados tempo e espaço, através dos quais pessoas aplicam recursos (materiais ou simbólicos) para agirem juntas no mundo". Apropriando-se da terminologia do materialismo histórico-geográfico de Harvey (1992) e da ontologia desconstrucionista do discurso de Laclau e Mouffe (1987), Chouliaraki e Fairclough (1999) explicam-nos que toda e qualquer prática social articula diferentes elementos da vida social como seus momentos, de forma que cada momento internaliza outros sem haver redução entre eles, em uma relação dialética.

A articulação é toda prática que estabelece uma relação entre elementos, cujas identidades modificam-se como efeito dessa prática. A totalidade resultante dessa prática articulatória, com esse caráter simbólico, isto é, sobredeterminado, define-se como sendo discurso. Os momentos são as posições diferenciais que são articuladas no interior do discurso (LACLAU e MOUFFE, 1987, p. 124), isto é, identidades relacionais que se articulam, formando o próprio discurso. Os elementos, por sua vez, são as diferenças que não são articuladas discursivamente. Nessa perspectiva, define-se discurso como o momento semiótico de uma prática social que se relaciona dialeticamente a outros. Esta lógica de articulação não se refere apenas à prática social, mas também ao próprio momento do discurso. O momento discursivo de uma prática, como afirma Resende (2008, p. 195), é o resultado da "articulação de recursos simbólicos/discursivos (como gêneros, discursos, estilos), articulados com relativa permanência como momentos (m) do Momento (M) do discurso".

Nessa perspectiva, o discurso é um momento semiótico da prática social midiática que (in)forma o evento e que este momento, ao internalizar e articular elementos, também opera como prática, à 
maneira de um sistema organizador e classificador dos acontecimentos do escândalo e de seus participantes, compondo uma configuração de recursos nas formas de agir, de representar e de identificar. Sendo o discurso prática articulatória de significação, o texto consiste na unidade do discurso. Quando partimos do discurso para a instância do texto, as formas de agir referem-se a gêneros, as formas de representar correspondem a discursos e as formas de identificar dizem respeito a estilos. Como explica Fairclough (2003), podemos distinguir os gêneros como maneiras de (inter)agir, as representações como discursos que figuram o mundo material de modos distintos e as identificações como estilos, isto é, modos de ser, sejam de identidades sociais, sejam de pessoas em particular.

Neste artigo, dedico-me particularmente ao discurso como forma de ação, com foco sobre o gênero discursivo da notícia, dado o seu papel essencial na "formação do leitor, capaz de entender, integrar-se e atuar na realidade social em que está inserido, via a formação de opiniões e mediante o desenvolvimento da capacidade de reflexão" (BENASSI, 2009, p. 1791), o que torna a notícia um modo de (inter)ação poderoso quanto à participação dos cidadãos na esfera pública e suas deliberações. Ao compreender que o gênero discursivo é o aspecto especificamente discursivo dos "modos de agir e interagir no curso de eventos sociais" (FAIRCLOUGH, 2003, p. 59), considero para análise, em especial, o mecanismo da cadeia de gêneros textuais. Como explica Fairclough (2001, 2003), a cadeia de gêneros, como fenômeno de intertextualidade, são formas específicas de agrupamento genérico: cadeias são "diferentes gêneros que se ligam regularmente, envolvendo transformações sistemáticas de gênero para gênero" (FAIRCLOUGH, 2003, p. 31).

É certo dizer que as notícias sobre escândalos políticos podem mobilizar uma variedade interminável de tipos de textos, pelo fato de tais eventos serem complexos e relativamente extensos no tempoespaço e pela natureza híbrida da notícia, especialmente no meio digital. No entanto, o que faz caracterizar uma cadeia de gêneros é o seu caráter sistêmico (FAIRCLOUGH, 2001). A regularidade das combinações de gêneros é particularmente útil para a análise social do escândalo político à medida que estabelece o vínculo entre os gêneros e as práticas sociais, isto é, as práticas de instituições, de esferas institucionais. Importa, pois, identificar as cadeias de gêneros mobilizadas nas notícias porque elas podem indicar relações 
estruturais entre distintos campos da sociedade e revelar o lugar e o modo de constituição do escândalo político.

\section{Procedimentos metodológicos de análise}

Considero os textos para análise apenas quanto aos mecanismos articulados em linguagem verbal. Julgo que o processo de significação do evento no discurso midiático dá-se prioritariamente através de sintagmas oracionais, que, compondo os textos que informam o escândalo, são responsáveis também pelo modo como os(as) leitores(as) interligam os demais elementos semióticos mobilizados nas notícias, como imagens e vídeos, construindo, assim, uma unidade de sentido no processo de leitura, compreensão e interpretação.

Na primeira etapa da análise, deu-se a identificação das duas principais instâncias discursivas de mídia do "Petrolão", a saber, as revistas semanais Veja e Carta Capital, e a sua classificação como instâncias discursivas de mídia corporativa e alternativa, respectivamente.

Com a expressão instância discursiva de mídia corporativa, refiro-me à comunicação baseada no acesso privilegiado e preferencial a recursos financeiros e simbólicos valorizados em nossa cultura. Entendo a atuação desses veículos como carriergroup: são mídias que "operam na massificação de um determinado olhar e produção de sentido sobre um acontecimento" (CASTILHO, LIMA, 2014, p. 177). Por isso, o veículo que seleciono como representante dessa instância é a revista Veja. Fundada em setembro de 1968, durante o regime militar brasileiro, Veja é a maior publicação no país em números absolutos: faz circular cerca de 862 mil exemplares por semana, com mais de 6 milhões de leitores e 30 milhões de usuários no site $^{3}$. Pertence ao Grupo Abril, um dos maiores conglomerados de comunicação e distribuição da América Latina, que possui mais de 90 títulos e sites, entre mídias, distribuição, licenças, assinaturas, big data, operação e-commerce, eventos, branded content e gráfica. Em 2017, Veja obteve a maior

\footnotetext{
3 "Veja", PubliAbril, s/d. Disponível em: <http://publiabril.abril.com.br/marcas/veja $>$.
} Acesso em: 19 mar. 2017. 
receita de sua história (48\% maior que a de 2016) com a venda de anúncios publicitários e passou a fazer circular pelo menos $20 \mathrm{mil}$ exemplares a mais por edição do que nos anos anteriores ${ }^{4}$.

Identifico como instância discursiva de mídia alternativa o tipo de comunicação que assume uma postura de resistência aos modelos de cognição social instituídos pelos grupos de mídia dominantes. Como esclarece Grinberg (1987, p. 20), a expressão comunicação alternativa identifica aqueles meios de comunicação que fazem "frente aos grupos que usufruem, em proveito de setores privilegiados (econômicos e/ou políticos), a propriedade e/ou controle dos meios de informação". Desmonopolizando ou pulverizando as movimentações de significação no "Petrolão", escolho como exemplar a revista Carta Capital. Lançada em 1994, hoje é publicada semanalmente pela Editora Confiança, que possui, além da Carta, apenas mais dois títulos, a Carta na Escola e a Carta Fundamental, mantendo, ainda, algumas colunas e blogs independentes e uma unidade produtora audiovisual, a TV Carta. Com queda progressiva no índice de circulação nacional por edição, saindo da média de 29.513 em $2014^{5}$ para 20.594 no primeiro semestre de $2017^{6}$, enquanto Veja alcançou crescimento de $8 \%$ na mesma época, Carta tem se mobilizado cada vez mais no meio virtual, com quase 2 milhões de seguidores.

Identificadas e classificadas as revistas Veja e Carta Capital, seguimos para a segunda etapa metodológica de análise, que consiste na definição e organização do corpus para exame.

O primeiro passo é a organização narratológica do escândalo, considerando o intervalo temporal de 2014 a 2016. É comum que no decorrer do escândalo surjam elementos surpreendentes, como novas

\footnotetext{
4 "Revista Veja supera 48\% em sua receita publicitária de janeiro", Grupo Abril, s/d. Disponível em: <http://www.grupoabril.com.br/pt/imprensa/releases/revista-vejasupera-em-48-sua-receita-publicitaria-de-janeiro/>. Acesso em: 19 mar. 2017.

5 "Circulação de revistas semanais", Associação Nacional dos Editores de Revistas (ANER), s/d. Disponível em: <http://www.aner.org.br/dados-de-mercado/circulacao> Acesso em: 14 jun. 2017.

6 "Veja cresce $8 \%$ em circulação e chega a $80 \%$ de participação de mercado", Exame, 3 jul. 2017. Disponível em: <https://exame.abril.com.br/negocios/dino/veja-cresce-8em-circulacao-e-chega-a-80-de-participacao-de-mercado-shtml/>. Acesso em: 22 jul. 2017
} 
denúncias, novos personagens, novas transgressões, que reconfiguram o relato do evento continuamente. Dada essa natureza do escândalo, Thompson (2002) propôs entendê-lo a partir de sua organização em quatro fases de desenvolvimento narratológico: i) pré-escândalo, quando surgem as denúncias; ii) escândalo propriamente dito, quando o evento se desdobra; iii) clímax, quando o escândalo alcança sua fase mais crítica, por exemplo, com confissões de culpa, renúncias, demissões e julgamentos; e iv) consequências, quando se dão avaliações acerca dos fatos e se discutem seus efeitos sobre a vida dos sujeitos envolvidos.

Segundo Motta (2013, p. 97), na narratologia, dispõem-se unidades temáticas, isto é, "intrigas que contenham princípio, meio e final de uma estória única (como aliás fazem, de maneira natural, os leitores, ouvintes e telespectadores nos atos de recepção)". Tais unidades temáticas são tratadas, aqui, em termos de sequências narrativas. A sequência narrativa é uma série lógica de núcleos, em que as unidades são ameaçadas à medida que "a dimensão temporal, sobre a qual se encontram situadas, é 'dicotomizada' em um antes vs um depois" (BARTHES, 1975, p. 63). Essa dicotomia corresponde à reviravolta da situação, às mudanças de tema entre um momento e outro do escândalo. Assim, organizo a progressão informacional do "Petrolão" em quatro sequências narrativas, que são estruturadas em quatro núcleos temáticos, conforme ilustra o Quadro 1, que o(a) leitor(a) verá mais à frente.

Delimitadas as sequências da narratologia do "Petrolão", passamos ao segundo passo, que é a coleta do corpus. Organizo o conjunto de dezenas de notícias publicadas pelas revistas, em ambiente digital, de acordo com o período referente às sequências narrativas do escândalo. Para isso, seleciono aquelas notícias cujo conteúdo considero mais diretamente associado à unidade temática de cada período da narrativa. Elejo, para cada sequência, duas notícias, uma de cada revista, a partir do que chamo de perfil contrastivo entre os textos. Por contraste, refiro-me ao tipo de relação entre os textos que é definida por contradições ou momentos de divergência acerca do que está sendo informado, à maneira de um efeito de paralaxe, em que há deslocamentos na significação de um determinado objeto-de-discurso em razão dos pontos de vista de abordagem. Ao todo, são oito notícias compondo o corpus para análise discursivo-textual. 
Sintetizo, no quadro 1, a delimitação da semiose discursivotextual do evento para análise, exibindo a seleção e a organização do corpus:

$$
\begin{gathered}
\text { Quadro } 1 \text { - Organização narrativa do "Petrolão": seleção e } \\
\text { organização do corpus. }
\end{gathered}
$$

\begin{tabular}{|c|c|c|c|}
\hline $\begin{array}{c}\text { Sequência } \\
\text { narrativa }\end{array}$ & $\begin{array}{l}\text { Unidade } \\
\text { Temática }\end{array}$ & $\begin{array}{c}\text { Revista } \\
\text { Veja }\end{array}$ & $\begin{array}{c}\text { Revista } \\
\text { Carta Capital }\end{array}$ \\
\hline I & $\begin{array}{l}\text { Deflagração da } \\
\text { Operação Lava Jato } \\
\text { pela PF } \\
\text { (Período: de março de } 2014 \\
\text { a setembro de 2014) }\end{array}$ & $\begin{array}{l}\text { Notícia - } \\
\text { Fornecedores da } \\
\text { Petrobrás sob } \\
\text { suspeita financiaram } \\
\text { campanha de } 121 \\
\text { parlamentares em } \\
\text { atividade. } \\
\text { Publicação: 07/05/2014 }\end{array}$ & $\begin{array}{l}\text { Notícia - Operação } \\
\text { Lava Jato está nas } \\
\text { mãos de Sérgio Moro } \\
\text { e Rodrigo Janot. } \\
\text { Publicação: } 10 / 09 / 2014\end{array}$ \\
\hline II & $\begin{array}{l}\text { Eleições presidenciais } \\
\text { de } \mathbf{2 0 1 4} \\
\text { (Período: de outubro de } \\
2014 \text { a janeiro de } 2015 \text { ) }\end{array}$ & $\begin{array}{l}\text { Notícia - Dilma e } \\
\text { Lula sabiam da } \\
\text { roubalheira na } \\
\text { Petrobrás, segundo } \\
\text { Youssef. } \\
\text { Publicação 23/10/2014 }\end{array}$ & $\begin{array}{l}\text { Notícia - TSE: a } \\
\text { publicidade da VEJA } \\
\text { é propaganda } \\
\text { eleitoral. } \\
\text { Publicação: } 25 / 10 / 2014\end{array}$ \\
\hline III & $\begin{array}{l}\text { Desestabilização do } \\
\text { governo de Dilma } \\
\text { Rousseff } \\
\text { (Período: de fevereiro de } \\
2015 \text { a dezembro de } 2015 \text { ) }\end{array}$ & $\begin{array}{l}\text { Notícia - O penúltimo } \\
\text { degrau da Lava Jato. } \\
\text { Publicação: } 19 / 06 / 2015\end{array}$ & $\begin{array}{l}\text { Notícia - As } \\
\text { consultorias na mira } \\
\text { da Lava Jato. } \\
\text { Publicação: 03/07/2015 }\end{array}$ \\
\hline IV & $\begin{array}{l}\text { O processo de } \\
\text { impeachment de Dilma } \\
\text { Rousseff } \\
\text { (Período: janeiro de } 2016 \text { - } \\
\text { outubro de 2016) }\end{array}$ & $\begin{array}{l}\text { Notícia - Senado } \\
\text { encerra mandato de } \\
\text { Dilma e fecha ciclo de } \\
\text { poder no PT. } \\
\text { Publicação: } 31 / 08 / 2016\end{array}$ & $\begin{array}{l}\text { Notícia - Senado } \\
\text { aprova impeachment } \\
\text { e destitui Dilma. } \\
\text { Publicação: } 31 / 08 / 2016\end{array}$ \\
\hline
\end{tabular}

Fonte: criado pelo(a) autor(a)

Por fim, a terceira etapa metodológica consiste no trabalho de identificação e categorização dos gêneros textuais articulados nas oito notícias selecionadas. Para isso, considero os seguintes modos 
de encadeamento de gêneros: i) quando a notícia inclui excertos de textos de outra esfera social, ii) faz menção a uma atividade de outro campo e iii) dispõe hiperlinks de acesso a outros textos no corpo da notícia. Com isso, chegamos ao quadro 2 :

Quadro 2 - Gêneros mobilizados em Veja e Carta Capital

\begin{tabular}{|l|c|lc|}
\hline \multicolumn{2}{|c|}{ VEJA } & \multicolumn{2}{c|}{ CARTA CAPITAL } \\
\hline Gênero & Ocorrência & \multicolumn{1}{c|}{ Gênero } & Ocorrência \\
depoimento & 8 & notícia & 14 \\
entrevista & 3 & depoimento & 4 \\
declaração oral & 3 & liminar & 3 \\
conversa & 2 & Relatório & 3 \\
reportagem & 2 & decisão judicial & 3 \\
lei/artigo de lei & 2 & petição & 3 \\
sentença condenatória & 2 & lei/artigo de lei & 2 \\
tratados jurídicos & 2 & laudo pericial & 2 \\
registros (do TSE) & 1 & Conversa & 2 \\
recursos (no STF) & 1 & Despacho & 2 \\
documentos (do DOPS) & 1 & mandado & 1 \\
Despacho & 1 & reportagem & 1 \\
libelo acusatório & 1 & recurso de defesa & 1 \\
mandado & 1 & Entrevista & 1 \\
interrogatório & 1 & carta & 1 \\
declaração de voto & 1 & pronunciamento & 1 \\
decisão judicial & 1 & decreto & 1 \\
discurso oral de defesa & 1 & declaração & 1 \\
& & libelo acusatório & 1 \\
& & & 1 \\
\hline
\end{tabular}

Fonte: criado pelo(a) autor(a).

Adiante, o trabalho se dedica a mostrar e discutir os dados demonstrados nos quadros 1 e 2 . 


\section{A configuração do escândalo político do "Petrolão": os campos sociais da política, do judiciário e da mídia}

Ao chegarmos aos gêneros mobilizados nas notícias que (in)formam o escândalo da Petrobrás, definimos os domínios sociais cujas práticas, em uma rede complexa e contingencial de entrecruzamentos na esfera pública, constituem a configuração do evento. Podemos conceber esses domínios ou esferas sociais a partir da noção de campo ${ }^{7}$. Campos consistem em espaços da estrutura social, mais ou menos restritos, que possuem suas próprias regras, princípios e hierarquias (BOURDIEU, 2004), e onde ações e interações ocorrem de acordo com certas normas e sob certas condições. As notícias deslocam gêneros de um lugar de origem para outro, de modo a compor a mediação textual do escândalo político de modo sistemático e regular. À luz de Fairclough (1999), que se apropria das reflexões sobre mediação de Silverstone (2002) e de Smith (1990), aqui, o termo mediação faz referência ao processo dinâmico da significação do escândalo político pelo movimento de um texto a outro operado através de notícias. $\mathrm{Na}$ análise empreendida, os gêneros encadeados apontam para as práticas sociais dos campos da política, do judiciário e da mídia.

O primeiro campo identificado é o da política. Trata-se do domínio social por excelência dos escândalos políticos, ou seja, aquele que justifica sua natureza política propriamente dita. É um domínio da sociedade que possui como elemento discriminador a atuação da chamada classe política, que, como define Bobbio (2017), é o conjunto de pessoas que constitui a elite do poder nas formas de governo presidencial e parlamentar. Os agentes políticos atuam na

\footnotetext{
${ }^{7}$ Quem inaugurou o gesto de abordagem do EP a partir da categoria de campo foi o sociólogo Thompson (2002), cuja teoria social do escândalo político serve de referência ao meu trabalho. $\mathrm{O}$ autor propõe pensar o evento situando-o no campo da política, em contato com o campo da mídia. Avançando a discussão, nesta tese, procuro mostrar que o EPM não se situa em somente um campo (o da política), que possui contato com outro campo (o da mídia), mas em um espaço de interseção, marcado por conflitos e tensões, entre três campos, constituindo a formação discursiva mesma do escândalo.
} 
regulação do poder na sociedade, seja coativo (para garantir a coexistência e impedir a desagregação da sociedade) ou físico (que se dá através do uso da força). O campo da política no "Petrolão" é evidenciado, na análise, pelos gêneros que pertencem a práticas sociais relacionadas às instituições (e seus membros) da Câmara dos Deputados, do Senado Federal, da Chefia do Poder Executivo, dos partidos políticos e dos próprios atores políticos.

Veja articula somente gêneros orais e no escopo do julgamento de impeachment no senado federal (ao todo, são 3 gêneros encadeados): o interrogatório realizado pelos senadores, a declaração de voto dos parlamentares e o discurso de defesa de Dilma Rousseff. Enquanto isso, Carta incorpora 2 gêneros orais, extraídos de práticas distintas (o pronunciamento do senador Romero Jucá anunciando a retirada do MDB da base de apoio do governo petista no diretório nacional do partido e a declaração do senador Rondolfe Rodrigues em plenária durante o julgamento de impeachment), e 1 gênero escrito (a carta assinada por Temer direcionada à então presidente Dilma). Ao priorizar gêneros da oralidade, Veja investe no potencial emotivo do discurso informante. Além disso, Veja centraliza a significação do escândalo, focando o acontecimento particular do impeachment, enquanto Carta a descentraliza, incorporando gêneros em referência a outros acontecimentos.

O segundo campo identificado é o do judiciário. Em Veja, foram incorporados 11 gêneros do campo do judiciário, o que corresponde a $57,89 \%$ do total de gêneros encadeados nas 4 notícias analisadas: depoimentos (de delação premiada), lei ou artigo de lei, sentença, tratados jurídicos, registros do TSE, recursos no STF, documentos do DOPS, despacho, mandado, libelo acusatório e decisão judicial. Tais gêneros estão relacionados exclusivamente às atividades da Operação Lava Jato e aos processos jurídicos em torno do impeachment. Em Carta, foram ao todo 14 gêneros incorporados: depoimento (de delação premiada), liminar, relatório (referente à operação Lava Jato e à Castelo de Areia), decisão judicial, petição, lei ou artigo de alei, laudo pericial, conversa (referente aos grampos realizados pela política envolvendo Dilma e Lula e Sérgio Machado e Romero Jucá), despacho (com ordens de juízes), mandado, recurso de defesa, decreto, libelo acusatório e parecer (referente às contas do governo Dilma reprovadas pelo TCU). Isso representa cerca de $70 \%$ 
da totalidade da rede genérica mobilizada pela revista, estando relacionados não apenas à Operação Lava Jato e ao impeachment, mas também às várias práticas de transgressão referidas no conjunto de notícias examinado.

Dois aspectos importantes desses encadeamentos são o grau de abstração dos gêneros e o acesso como forma de controle e dominância. Dos 11 gêneros articulados em Veja, 5 são incorporados sem especificidade de fonte de lugar, de participantes envolvidos na atividade ou de conteúdo. Isso indica que a tradução desses gêneros para a audiência é marcada pelo predomínio da voz da própria revista e pelo forte controle sobre a seleção e exposição das produções textuais da esfera do judiciário. Em Carta, o grau de abstração não se mostrou presente, pois todos os gêneros encadeados foram descritos, contextualizados ou tiveram excertos da produção textual original citados direta ou indiretamente. Em Veja, encontramse gêneros da conversa privada (com autoridades da força-tarefa da Lava Jato e com o então presidente do senado Renan Calheiros) e o gênero do depoimento, particularmente o da delação de Alberto Youssef e Paulo Roberto Costa, publicados pela revista quando ainda estava sob sigilo de justiça. Esses gêneros da conversa privada e do depoimento de acesso exclusivo e antecipado indicam a dominância que a mídia corporativa exerce sobre a mediação textual do "Petrolão", mantendo relação direta com subcampos do campo do judiciário, o que não se vê em Carta, cujo raio de acesso a subcampos parece inexistente ou não aparente. A revista encadeia depoimentos de delação premiada, mas apenas depois de oficialmente declarados públicos.

O terceiro campo identificado é o da mídia. O domínio social dos meios de comunicação exerce função constitutiva no desenvolvimento do "Petrolão", e, como se tem visto historicamente, no próprio modo de operação do sistema de eleições no país, pois esta esfera, no período de disputa entre os candidatos, torna-se a "arena central onde a luta por poder simbólico é travada" (THOMPSON, 2002, p. 139). O campo de atuação dos media é o principal lugar onde os agentes políticos relacionam-se com o eleitorado, mostrando suas propostas de governança e gerenciando suas imagens particulares, compondo o que Bourdieu (1984, p. 114) chama de capital simbólico, que corresponde aos "rituais de reconhecimento social, abrangendo os demais tipos de capitais", 
como o cultural, o econômico e o social.

Veja possui uma cadeia composta por 19 diferentes gêneros textual-discursivos, dos quais o mais presente na rede tecida é o a notícia: notícia (8), reportagem (3), entrevista (2) e declaração oral dada à imprensa (2). Das 8 vezes em que notícias foram incorporadas, todas referiram-se a matérias da própria revista. Em Carta Capital, são 20 gêneros ao todo, sendo também o mais frequentemente articulado o da notícia: notícia (14), reportagem (1) e entrevista (1). As notícias, apresentadas a partir do recurso de hyperlink, são dispostas apenas em duas das quatro notícias, distintamente do que houve em Veja, em que as notícias incorporadas foram distribuídas ao longo dos quatro textos examinados. Enquanto Veja restringe-se à Lava Jato e ao impeachment, Carta faz referência a outras operações da PF, como a Castelo de Areia, e a outras atividades de transgressão. Assim, além da autorreferenciação, em Veja, encontramos centralização da pauta, diferentemente do que ocorre em Carta, que descentraliza o "Petrolão".

A incorporação de notícias e reportagens nos textos estabelece relações tanto retrospectiva quanto prospectivamente, pois os links movem a audiência espacial e temporalmente. A recursividade constante e a mobilização de leitores no espaço-tempo são formas do exercício de poder como controle, pois induzem a audiência a permanecer no domínio de produção de significações da instância discursiva midiática e caracterizam uma disputa pela hegemonia informacional do "Petrolão".

\section{Notas conclusivas}

Ao fim do trabalho de análise, revela-se que há uma relação sistemática e regular entre notícias, cadeias de gênero e práticas sociais de domínios institucionais. Verifica-se que a configuração constituinte do escândalo político do "Petrolão" dá-se, assim, no âmbito da interseção entre os campos sociais da política, do judiciário e da mídia: 
Figura 1 - Âmbito do escândalo político "Petrolão"

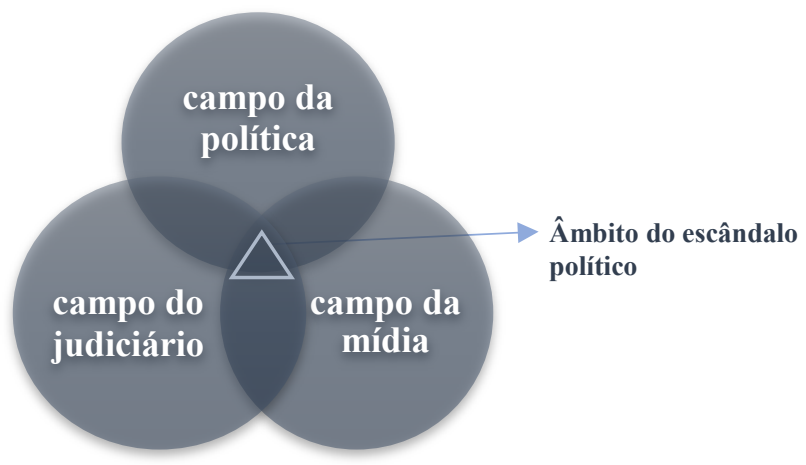

Fonte: criado pelo(a) autor(a).

Com base na identificação dos três campos sociais, é certo que não cabe pensar a disposição estrutural do "Petrolão" apenas quanto à discriminação de domínios da sociedade. Cada domínio, como campo, busca realizar os seus próprios interesses e, apesar de episódios de tensão, vê-se que mantêm mútua dependência. Esses campos interagem entre si, suas práticas se dão em entrecruzamentos constantes e atuam, parcialmente, em estratégias de gerenciamento da produção semiótica do escândalo ao mesmo tempo em que se confrontam na (re)produção multiforme de relações de controle e domínio.

A identificação de tais campos revela uma importante dimensão da constituição do escândalo político: sua natureza discursiva e textual. Assim, um grande desafio para a mudança em nossa cultura de escândalos é a compreensão de que não cabe mais pensá-los como simples episódios polêmicos nas disputas eleitorais, frequentemente vinculados a julgamentos morais de conduta sobre um político ou partido em particular. É tempo de reconhecer a constituição discursiva e textual do escândalo político, pois sua análise revela como o evento envolve estruturas de funcionamento de poder em interação na sociedade em determinado tempo e espaço, sua natureza constituinte figurada pela interseção entre os campos 
sociais da mídia, da política e do judiciário, seus modos de operação e efeitos. Diante dos resultados aqui apresentados, cabe reconhecer o que é, a um só tempo, limite deste trabalho e convite para investigações futuras: estabelecida a interseção entre os campos sociais, que formas de poder estão presentes nessa interação?

\section{REFERÊNCIAS}

BAKHTIN, M. M. O problema do texto. In: BAKHTIN, M. M. Estética da criação verbal. Trad. Maria Ermantina Galvão Gomes Pereira. São Paulo: Martins Fontes, 1992, p.327-358.

BARTHES, R. 1975. A Retórica Antiga. In: COHEN, J. Pesquisas de Retórica. Petrópolis: Vozes, 1975.

BEAUGRANDE, R. New foundations for a science of text and discourse. Norwood: Ablex, 1997.

BENASSI, M. V. O gênero "notícia": uma proposta de análise e intervenção. In: CELLI - Colóquio de Estudos Linguísticos e Literários. Anais. Maringá, 2009, p. 1791-1799.

BOBBIO, N. Estado, governo, sociedade: fragmentos de um dicionário político. 20 ed. Rio de Janeiro: Paz e Terra, 2017.

BOURDIEU, P. A economia das trocas simbólicas. São Paulo: Perspectiva, 1974.

BOURDIEU, P. A produção da crença: contribuição para uma economia dos bens simbólicos. São Paulo: Zouk, 2004.

BOURDIEU, P. O poder simbólico. Rio de Janeiro: Bertrand Brasil, 1998.

BOURDIEU, P. Questions de sociologie. Paris: Les Éditions de Minuit, 1984.

CASTILHO, M.; LIMA, T. A pauta na capa: a mídia corporativa como porta-voz do controle e ordem social na cidade do Rio de Janeiro. Liinc em Revista, Rio de Janeiro, v.10, n.1, p.176-194, 2014. 
CAVAlCANTE, M. Os sentidos do texto. São Paulo: Contexto, 2016.

CHOULIARAKI, L.; FAIRCLOUGH, N. Discourse in Late Modernity. Edinburg: Edinburg University Press, 1999.Disponível em: http://www.unisul.br/paginas/ensino/pos/linguagem/04

03/05.htm>. Acesso em: 10 fev. 2013.

FAIRCLOUGH, N. L. A análise crítica do discurso e a mercantilização do discurso público: as universidades. In: MAGAlHÃES, C. (Org.). Reflexões sobre a análise crítica do discurso. Belo Horizonte: Ed. UFMG, 2001.

FAIRCLOUGH, N. L. Analysing discourse: textual analysis for social research. London: Routledge, 2003.

FAIRCLOUGH, N. L. Critical and descriptive goals in discourse analysis. Journal of Pragmatics, v. 9, p. 739-763, 1985. Disponível: $<$ https://www.sciencedirect.com/science/article/abs/pii/03782166859 00025>. Acesso em: 10 jan. 2017.

FAIRCLOUGH, N. L. Discourse, social theory, and social research: the discourse of welfare reform. Journal of Sociolinguistics, v. 4, n. 2 p. 163-195, 2000. Disponível em: $<$ https://www.researchgate.net/publication/227689051_Discourse_S ocial_Theory_and_Social_Research_The_Discourse_of_Welfare_Re form $>$. Acesso em: 23 set. 2017.

FAIRCLOUGH, N. L. Teoria social do discurso. Brasília, DF: Ed. UnB, 2001 a.

. Language and power. New York: Longman, 1989.

FAIRCLOUGH, N.; JESSOP, R.; SAYER, A. Critical realism and semiosis. Journal of Critical Realism, v. 5, n. 1, 2002. Disponível em:

$<$ https://www.researchgate.net/publication/313037147_Critical_reali sm_and_semiosis $>$. Acesso em: 18 set. 2017.

. Análise crítica do discurso como método na pesquisa científica social. Tradução de Iran Ferreira de Melo. Linha d'Água, n. 25, n. 2, p. 307-329, 2012. Disponível: 
$<$ http://www.revistas.usp.br/linhadagua/article/view/47728>. Acesso em: 29 jun. 2016.

GRINBERG, M. S. Comunicação Alternativa: dimensões, limites, possibilidades. In: A Comunicação alternativa na América Latina. Petrópolis: Editora Vozes, 1987.

HALLIDAY, M. A. K. Language as social semiotic: the social interpretation of language and meaning. Baltimore: University Park Press, 1978.

HARVEY, D. A condição Pós-Moderna. São Paulo: Edições Loyola, 1992. Loyola, 2008.

O neoliberalismo: história e implicações. São Paulo:

KOCH, I. Introdução à Linguística Textual: trajetória e grandes temas. São Paulo: Martins Fontes, 2004.

KOCH, I.; ELIAS, V. Ler e compreender: os sentidos do texto. São Paulo: Contexto, 2006.

LACLAU, E.; MOUFFE, C. Hegemonía y estrategia socialista: hacia una radicalización de la democracia. Madrid: Siglo XXI, 1987.

MAGALHÃES, I. Introdução: a análise de discurso crítica. DELTA, v. 21, n. esp. p. 1-9, 2005. Disponível em: $<$ http://www.scielo.br/scielo.php?pid=S0102-

$44502005000300002 \&$ script $=$ sci_abstract\&tlng=pt $>$. Acesso em: 07 fev. 2013.

MAGALHÃES, I. Por uma abordagem crítica e explanatório do discurso. DELTA, v. 2, n. 2, 1986. Disponível em: $<$ https://revistas.pucsp.br/index.php/delta/article/view/31247>. Acesso em: 07 fev. 2013.

MAGALHÃES, I. Teoria crítica do discurso e texto. Linguagem em (Dis)curso, v. 4, n. esp., p. 113-131, 2004.

MOTTA, L. G. Análise Crítica da Narrativa. Brasília: Editora UnB, 2013.

MOTTA-ROTH, D. Popularização da ciência como prática social e discursiva. In: MOTTA-ROTH, D.; GIERING, M. E. 
(Orgs.). Discursos de popularização da ciência. Hipers@beres Volume I. Santa Maria, RS: PPGL Editores, 2009, p.131195. ALTHUSSER, L. 1969. For Marx. London, New Left Books, xp.

RESENDE, V. Análise de discurso crítica e etnografia: o movimento nacional de meninos e meninas de rua, sua crise e o protagonismo juvenil. Tese (Doutorado). Programa de pós-graduação em Linguística, UNB, Brasília, 2008.

THOMPSON, J. B. O escândalo político: poder e visibilidade na era da mídia. Petrópolis: Vozes, 2002.

Recebido em: 28/11/2019

Aceito em: 23/03/2020 